\title{
GENERAL INSTRUCTION
}

- Authors: Carefully check the page proofs (and coordinate with all authors); additional changes or updates WILL NOT be accepted after the article is published online/print in its final form. Please check author names and affiliations, funding, as well as the overall article for any errors prior to sending in your author proof corrections.

- Authors: We cannot accept new source files as corrections for your article. If possible, please annotate the PDF proof we have sent you with your corrections and upload it via the Author Gateway. Alternatively, you may send us your corrections in list format. You may also upload revised graphics via the Author Gateway.

\section{QUERIES}

Q1. Author: Please confirm or add details for any funding or financial support for the research of this article.

Q2. Author: please provide file size.

Q3. Author: Please provide the page range in Refs. [5] and [7].

Q4. Author: Please provide city for the University of Chieti-Pescara. 


\begin{abstract}
Introduction: To present technical content clearly and effectively for global users of English, engineering students need to learn how. About the case: Technical communication classes in Spain and the US engaged in an international telecollaborative project between cross-cultural virtual teams in which students in Spain developed oral presentations that were then peer-reviewed by counterparts in the US Situating the case: Research on international professional communication and, more specifically, virtual exchange is rapidly growing to explore how instructors can help students gain key competencies such as audience awareness, intercultural sensitivity, and an understanding of English as a lingua franca. Approach/methods: As part of the Trans-Atlantic \& Pacific Project network, this project focused on spoken communication. Data were analyzed from feedback forms used by US students to evaluate oral presentations, and on prelearning and postlearning reports completed by students in Spain, as well as from class discussions accompanying the project. Results/discussion: Through reflections on pragmatic strategies that facilitate exchange and collaboration in English as a lingua franca, the engineering students became more fully aware of the importance of rhetorical and linguistic factors that affect meaning-making for engineers internationally. Conclusion: Results suggest that students who participate in transnational virtual exchange projects integrate their desire to acquire knowledge with an awareness of the importance of sharing knowledge through mindful and inclusive communication practices. Technical and engineering communication instructors from different countries can heighten their students' audience awareness, and cultural and language sensitivities through such projects.
\end{abstract}

Index Terms-English as a lingua franca, internationalization, oral communication, telecollaboration, virtual exchange.

Manuscript received April 6, 2018; revised December 15, 2020; accepted December 17, 2020. Date of current version.

(Corresponding author: Bruce Maylath.)

Elisabet Arnó Macià is with the School of Engineering,

Universitat Politècnica de Catalunya (Barcelona Tech), 08800

Vilanova i la Geltrú, Spain (email: elisabet.arno@upc.edu).

Bruce Maylath is with the Department of English, North Dakota

State University, Fargo, ND 58108 USA (email:

bruce.maylath@ndsu.edu).

Massimo Verzella is with the School of Humanities and Social

Sciences, Pennsylvania State University, The Behrend College,

Erie, PA 16563 USA (email: muv56@psu.edu).

This article has supplementary downloadable material available at https://doi.org/10.1109/TPC.2021.3057246, provided by the authors. The files consist of a Chinese translation of the abstract by $Z$. Xi ( $82 \mathrm{kB}$ in size) and a Spanish translation of the abstract by $\mathrm{R}$. Anido ( $\mathrm{kB}$ in size).

IEEE 10.1109/TPC.2021.3057246
Although the literature on engineering communication pedagogy is replete with studies of technical writing and approaches to teaching it, research that focuses on engineers' oral communication skills is startlingly scarce. The small number of studies on this topic (e.g., [1], [2]) shows that competence in oral communication can help engineering professionals enhance their careers [3]. Technical communication today is characterized by complexity: Interlocutors may come from different cultural backgrounds, and their interactions may be conducted through the medium of computers and videoconferencing software. Undoubtedly, the rise of computer-mediated communication (CMC) has been accelerated by the COVID-19 pandemic and the development of technologies that facilitate collaboration in cross-cultural virtual teams (CCVT) [4]. Such online collaborations involve managing the complexity of international multilingual projects so that university instruction is experientially aligned with the realities of workplace scenarios [5].

Mohan et al. [6] refer to recommendations of the Accreditation Board for Engineering and 


\section{Practitioner Takeaway}

- Technical and engineering communication instructors from different countries can heighten their students' audience awareness and cultural and language sensitivities by organizing virtual exchange, a key project within the framework of internationalization at home.

- Engineering students who participate in transnational virtual exchange projects understand the pragmatics of the use of English as a lingua franca in international professional communication and gradually refine their ability to exchange information orally and remotely in cross-cultural virtual teams.

- The effective delivery of technical presentations depends on an ability to shed ethnocentric biases and narrow conceptualizations of rhetorical effectiveness to understand technical communication as an act of negotiation that requires patience, sensitivity, open-mindedness, and flexibility.

Technology (ABET) to emphasize the importance of preparing students for

communication, teamwork, understanding ethics and professionalism, engineering within global and societal context, lifelong learning, and knowledge of contemporary issues [6, p. 562].

The problem is that engineering students are rarely put in realistic engineering communicative situations that require them to collaborate with other people to achieve well-defined goals. For this reason, they find it difficult to understand the types of challenges that they need to overcome when they interact with both engineers and nonengineers, especially when these individuals are non-native speakers of English. In their review of research on industry needs, Donnell et al. [7] identified key weaknesses of engineering graduates in their ability to communicate with nonengineers, develop concise presentations for senior management and executives, and engage effectively in intercultural communication. More focused studies of oral presentation skills are scant [8]-[10]. This gap in research motivated us to develop the international virtual exchange project highlighted here.

\section{"Virtual exchange" is an umbrella term used to} designate collaborative projects that link classes in different countries. According to O'Dowd [11], the two main models for virtual exchange in foreign language education are the tandem model, in which speakers of different languages interact remotely and independently to improve their communication skills in two different languages, and the more structured the telecollaboration model, which often involves the creation and exchange of different types of texts between two groups of students. In this model, the teacher's role as language and communication expert is more prominent.
The goal of this teaching case is to analyze how telecollaboration projects can stimulate a reflection on the challenges of technical communication -challenges that become more pronounced when native (NS) and non-native speakers (NNS) of English need to exchange information orally and remotely, using English as a lingua franca (ELF). The language of international technical communication is not native English: NNSs use ELF.

Seidlhofer defines ELF as any use of English among speakers of different irst languages for whom English is the communicative medium of choice, and often the only option" $[12$, p. 7].

The fluid and context-dependent nature of ELF [13]-[15] makes it difficult to describe this functional language. But even in its fluidity, ELF exhibits patterns of regularity [12], [16], especially in the use of pragmatic strategies [17] to mediate interaction and achieve mutual understanding. Some of these strategies are:

1. Explicitation through frequent repetition and rephrasing

2. The joint construction of utterances; the creative use of metaphors

3. The use of comprehension checks and code-switching

In this telecollaboration project, ELF is not only the language for communication [18], but also becomes a necessary learning goal for both NS and NNS students [19] so they can adapt to the demands of international engineering communication. NS students, in particular, need to understand that failure to adjust speech in intercultural contact results in "unilateral idiomaticity" [20, p. 211], a type of miscommunication that occurs when native speakers fail to adjust their communicative 
strategies based on a careful and sensitive assessment of the needs of their interlocutors [20], [21]. To summarize, in a context in which engineering students from Spain and the US discussed authentic engineering projects, we wanted to determine whether telecollaboration can encourage students to become genuinely interested in the complex processes of mediation and accommodation that characterize technical communication in ELF.

Specifically, this article aimed to answer the following research question.

RQ. How can a telecollaborative oral communication project stimulate engineering students to reflect on rhetorical, linguistic, and cultural factors that affect the exchange of technical information?

To answer this question, we analyzed the implementation of a telecollaborative project by looking at planning and teaching procedures, students' outcomes as reflected in their feedback forms and prelearning and postlearning reports (a typical feature of Trans-Atlantic \& Pacific Project assignments to raise students' awareness [22]), and class discussions, a key element of telecollaboration projects. Such discussions, which form part of the debriefing stage, allow students to reflect on and take a critical stance toward their projects [11]. For this partnership, two types of discussion took place following the development of the project: one in each of the participating classes, the other linking both classes in real time through videoconferencing.

We believe that this article is relevant to technical and engineering communication (TEC) instructors from different countries, especially those who see the value of internationalization at home (IaH) initiatives [23], [24] that include but are not limited to virtual exchange. All too often, internationalization efforts are limited to the recruitment of foreign students or to the organization of study-abroad programs. Before 2020, the main barrier to student mobility was cost, but the COVID-19 pandemic added a new obstacle to study abroad, thus demanding that instructors design more IaH initiatives. A large-scale study conducted by Soria and Troisi shows that IaH projects can stimulate the development of students' intercultural competencies "as much as-if not more than-traditional study/travel abroad" [25, p. 273].
We start this teaching case by presenting the telecollaboration project that we organized and by situating the case within current scholarship on virtual exchange and recent studies conducted by members of the Trans-Atlantic \& Pacific Project (TAPP). Next, we illustrate our approach to the telecollaborative exchange, together with the organization of the teaching module for each of the participating classes. Then, we delineate the methods for collecting and analyzing data, followed by specific results of instructors' and students' work on the exchange. These results are discussed with a view to inspiring fellow TEC instructors to carry out telecollaborative partnerships.

\section{About the Case}

Our teaching case linked two technical communication courses: One offered at Universitat Politècnica de Catalunya (UPC, Catalonia, Spain) and the other at North Dakota State University (NDSU, USA). Both classes comprised engineering students. Their collaboration centered on the preparation and delivery of oral presentations based on real projects by UPC students.

Students' roles in the partnership involved authorship by the UPC students (non-native speakers of English) and peer review by the NDSU students (mostly native speakers of English). Peer feedback activities have long been part of the teaching of writing, and are considered beneficial for both the authors receiving feedback and the reviewers [26], [27]. In recent years, such activities have incorporated the mediation of technology, which includes other affordances such as planning, multimodality, and affective communication (e.g., [28]). The involvement of peers is also considered beneficial in the assessment of oral presentations ([29]).

\section{Course, Task, Goals, and Challenges: Spain}

Course The Spanish students were enrolled in an elective English for specific purposes (ESP) course focusing on project-based technical communication, offered in the last year of their bachelor's degree. The defining characteristic of ESP courses is that they are geared toward specific students' needs, drawing on the methodology, activities, texts, and language of their disciplines [30]. The course included technical writing and speaking, with the development of project-based 
the students' choice. Course deliverables included an oral presentation, abstract, and short report.

Task The class consisted of approximately 40 students (enrollment varied somewhat over the course of the term), divided into eight teams of 4-5 students. Each team worked collaboratively to produce an oral presentation on an engineering project. Students were encouraged to choose ongoing or past projects in which they had participated, thus making the course and the communication tasks more relevant.

Goals A chief goal for the UPC course was to put students in a realistic engineering communicative situation, in which they would have to present orally to an audience on a product or project that they had developed or were currently developing as part of their studies. The presentations had to be conducted in English, and that requirement posed the main challenge for the students who were used to communicating in either Catalan or Spanish (the two languages of the community) and for whom English is a foreign language. Therefore, this assignment involved a double hurdle for learners of English with varied levels of proficiency:

1. Communicating technical information.

2. Communicating in a foreign language.

Their partnership with counterparts in the US allowed them to reach a real international audience beyond the classroom. In doing so, it revealed to the students what is involved in delivering effective oral presentations about engineering projects using ELF.

Challenges The Spanish students faced the challenge of presenting their projects in front of a real audience, which helped them gauge the effectiveness of their communication in an experiential way, while as learners of English as a foreign language, they became aware of and gained practice in using English as the lingua franca of international engineering communication. The instructor faced the challenges of adjusting the teaching of spoken communication to the needs of different types of students and projects, teaching rhetoric and language to students for many of whom this course was their first contact with technical communication instruction. Additional challenges involved integrating teaching procedures in such a way that in a short time, students could become aware of and apply rhetorical and linguistic elements to their tangible outcomes (presentations for an international audience) in a short period of time.

\section{Course, Task, Goals, and Challenges: U.S.}

Course The US students were enrolled in Writing in the Technical Professions, an upper-division writing course that provides intensive practice in employing the conventions of professional genres to write about technical subjects for a wide range of audiences. In keeping with calls for designing globally networked learning environments [31], [32], telecollaboration projects at NDSU are designed to help students develop skills that enable them to produce effective scientific and technical documents for and in collaboration with an international audience.

Task The class consisted of 22 students organized into eight teams, which were matched with the Spanish authoring teams. Each team had to evaluate the presentation developed by the partner team at UPC and collaboratively formulate feedback comments that could help their partners fine-tune their presentations. More specifically, NDSU engineering students were asked to evaluate the rhetorical effectiveness of the technical presentations from the perspective of a North American audience. They also had to analyze the rhetorical strategies used by their peers and the type of English used in the presentations. The US students were not required to identify ELF strategies based on a list given to them, but they had to infer general strategies for mediation that the Spanish engineers tended to use in their oral presentations. This approach is based on the fact that ELF is not a style guide, but a communicative medium that is "intersubjectively constructed in each specific context of interaction" [33, p. 925]. Importantly, as they provided feedback to their peers, the NDSU students had to avoid unilateral idiomaticity.

Goals The primary goal for the NDSU course was to help students understand how ELF is used in intercultural communication. A related goal was to make students appreciate different rhetorical traditions in the presentation of technical content. To achieve these learning outcomes, students also had to appreciate the importance of audience awareness and accommodation in CMC, especially when interacting with people from different backgrounds. (The ability to collaborate effectively and efficiently in CCVTs has become even more crucial in the long aftermath of the COVID-19 
outbreak.) Finally, in their role as communication consultants (native speakers of English enrolled in a technical communication course), the NDSU students had to learn how to collaborate with peers who took on the role of subject-matter experts in light of their authorship and ownership of content shared in the oral presentations. This distribution of roles is not new within the TAPP, as attested by Maylath et al. [34].

Challenges A key challenge for the US students was understanding the concept of variation in the use of English. They had to act as communication consultants while coming to terms with the fact that native English, a variety that carries authority and prestige, can be a confusing code when used in intercultural communication. The concept of unilateral idiomaticity, in particular, is difficult to grasp for native speakers of any language because familiarity with a language makes it difficult to recognize the level of idiomaticity (and, hence, opacity) of common expressions like phrasal verbs in English, for example. Related challenges included making sense of rhetorical strategies for oral presentations that can be at odds with typical recommendations offered in US speech courses and finding efficient ways of collaborating in a CCVT. Challenges for the instructor included how to introduce students to the concept of ELF, how to discuss the impact of culture on rhetorical strategies for communication without reifying differences as walls that divide people, and how to promote socialization between the two groups of engineering students.

To summarize, the instructors wished to engage all their students in oral communication with a real international audience to raise awareness of the importance of understanding professional communication as an act of mindful mediation. As in the study by Fillenwarth et al. [35], this study too was designed to gauge the effect of "disciplinary acculturation" in classes arranged to "shape how students view themselves professionally as engineers" [16, p. 35].

Other more complex challenges emerged for both instructors, as partnerships of this type involve aligning two different technical communication courses - taught in different parts of the world and for different types of students-so that content, materials, and procedures would be negotiated in both classes, resulting in shared technical communication frameworks and teaching techniques that can serve a broader range of students and thus effectively prepare them for globalized TEC communication. A pathway for achieving this goal is precisely through experiential real-world learning opportunities, such as that afforded by this project.

\section{Situating the Case Within IEEE TPC LITERATURE}

In the last three years alone, this journal has devoted much space to studies that explore the pedagogical value of virtual exchange. Alaid et al. started their systematic examination of the literature on virtual teams by explaining why instructors should pay attention to virtual exchange [36]. They report on a survey that found that, of 1372 business respondents from 80 countries, $85 \%$ of the respondents worked on virtual teams. In her analysis of the effectiveness of a 7.5-week online global course on technical communication, Batova explored challenges and opportunities offered by virtual exchange while bringing attention to the mix of social and linguistic competencies that students of technical communication can develop when they interact with peers from diverse cultural backgrounds [37].

Although some studies have offered practical advice on how to establish effective global virtual teams [38], others have stimulated the conversation on theoretical approaches to the teaching of international professional communication. Walwema, in particular, explored the role of transliteracy in engendering dialogical imagination [39]. Engaging in transliteracy as a method of inquiry in intercultural communication allows students to go beyond cultural stereotypes and toward an exploration of differences in linguistic, social, or cultural behaviors as they emerge in the course of inquiry and among media. Transliteracy, she underlines, stimulates an appreciation of the complexities of different cultures through a "dialogue" with linguistic and nonlinguistic products and artifacts that offer thick descriptions of alien cultures. These alternative instructional materials should integrate the study of scholarly sources that tend to embrace a comparative/contrastive approach in framing intercultural communication.

As suggested above, our partnership linking engineering classes was conducted under the auspices of TAPP. Launched in the 1999-2000 academic year, TAPP comprises a loose network of university-level instructors who teach writing, usability testing, or translation studies. To date, it 
has linked scores of instructors and thousands of their students at 45 universities in 20 countries across nearly all of the world's continents: Africa, Asia, Europe, North America, and South America.

As first reported in IEEE International Professiona Communication Conference proceedings [40] and later updated in the pages of this journal [41], the vast majority of TAPP collaborations focus on written texts, mostly involving writing-translation projects. The theories supporting this pedagogical approach are delineated by Mousten et al. [42], and the basic framework of bilateral projects (pairs of classes) has been described by Humbley et al. [40] and Mousten et al. [41], while the more complex mechanisms of multilateral projects (i.e., linking up to seven classes) have been described by Maylath et al. [43]. The latter include examples of engineering students in technical writing courses who coauthored technical texts from their campuses in Spain and the US [34].

In more recent years, TAPP partnerships, like the one reported here, have been extended to include engineering students in projects that focus on oral texts and their delivery. These sorts of collaborations began in a project-focused technical communication course at UPC. Designed as a type of capstone course that runs parallel to students' final theses or realistic engineering projects, this course focused on effective technical communication in both speech and writing. For the purpose of this study, the students at UPC were matched with engineering students in a Writing in the Technical Professions course at NDSU. The latter critiqued the oral presentations from their perspective as native speakers of English. This arrangement, begun in 2015, was the first partnership involving spoken texts among any of the members of the TAPP teaching network.

With students grouped in CCVTs [44], [45], intercultural sensitivity and audience awareness become key elements and form part of the reflective work required of students. Underpinning the use of CCVTs in TAPP collaborations is the understanding that, in Ingrid Piller's words, "intercultural communication is a social practice" [46, p. 174] and thus that students' engagement with each other through CCVTs provides the social practice needed to help them learn experientially how best to communicate interculturally.

Purposeful use of CCVTs also reflects an understanding of Bosley's observation that "All cultures tend to be ethnocentric - that is, all tend to cling to the belief that their own culture is the standard by which others are to be judged" [47, p. 3]. Therefore, CCVTs serve as experiential catalysts leading students to confront their assumptions that their own cultures are standard or even "best." or the two of us, coauthors who teach in the US, it ; paramount to puncture our American students' often subconscious but self-righteous notions of ethnocentricity and of perceiving anything American as automatically being superior. Like Thatcher [48, pp. 343-344], we recognize that the US educational system likes to claim attention to diversity but in reality honors and attends only to surface features while imposing homogeneous US values.

\section{Methods}

Project Organization Below is a summary of how the telecollaboration was chronologically organized between the two classes at UPC and NDSU during a three-month period.

1. Project teams were organized at UPC, with each team selecting a real (or, at least, realistic) engineering project for the course (the oral presentation being one of the course deliverables, along with a written report).

2. The exchange was organized by matching UPC teams with pairs of reviewers at NDSU, whenever possible according to students' precise disciplines (e.g., electrical engineering students at both sites), and it was developed in the following phases:

a. Preparing oral presentations (UPC)

b. Performing dry runs in class and videorecording the final version of the presentations outside class (UPC)

c. Developing feedback criteria (NDSU)

d. Engaging in informal communication using a Facebook group (UPC-NDSU)

e. Posting the videos on Facebook (UPC)

f. Watching and discussing presentations in class (NDSU)

g. Completing feedback forms to be emailed to UPC students (NDSU)

h. Communicating via email (UPC-NDSU)

i. Using a live videoconference to clarify and further discuss the feedback received earlier by email and Facebook (UPC-NDSU)

To elaborate on Phase 2b: First, UPC students delivered the presentations live in front of the course instructor and fellow students, who gave feedback to the presenters. Then, they used the 
feedback received at UPC to develop a second version of their presentation. The delivery of this second version was recorded and stored as a video file, which was then shared with NDSU students through a private Facebook group.

\section{Organization of the Presentations (Spanish \\ Students) Teams of Spanish students had to} prepare a 10-minute oral presentation, targeted to their desired audience and purpose. To this extent, the teams were free to define the audiences for their message. They were also allowed to make the purpose of their presentations informative or persuasive. Thus, their intended audiences ranged from company managers to engineering experts to lay persons. The students were directed to follow course guidelines on how to prepare oral presentations. The guidelines covered determining the content of technical presentations (especially informative-persuasive), the process of preparing an oral presentation (analyzing audience and purpose, structuring the presentation, deciding on content), the use of language (signposting, characteristics of spoken language, etc.), and delivery (features of effective presentations).

The Spanish engineering students could choose the technical topics for their presentations, and were encouraged to present on projects in which they had participated. Thus, topics ranged from robotics and automation to electrical and mechanical engineering (development of vehicles), and a variety of industrial design and product development projects. As the UPC students were learners of English as a foreign language, with varied proficiency in English, the course focused on written and spoken technical communication from a problem-solving perspective (see, e.g., [49], [50]) and integrated a genre- and process-based pedagogy [52], [52]. Such an approach is particularly appropriate for ESP courses, as it combines the formal characteristics of genre with the communicative processes where the instructor helps students gradually construct the text while catering to a variety of needs and proficiency levels. Participation in the TAPP collaboration brought more realism to the course by providing an authentic international experiential learning scenario.

\section{Organization of the Peer Review (American Students) Early in the semester, the NDSU} instructor conducted several workshops and class activities on audience analysis, rhetorical patterns in engineering communication, strategies for oral presentations, the use of visual aids in technical presentations, cross-cultural rhetorics, and the concept of ELF. The U.S. students were also introduced to intercultural communication research through presentations that briefly illustrated classic studies conducted by Geert Hofstede [53] and new approaches proposed by other scholars (e.g., Piller [46]) who critiqued the essentialist view of the nation as the foundation of culture.

The two instructors collaborated in developing a feedback form to elicit NDSU students' reactions to UPC students' presentations. Since the peer review task was the crucial part of the partnership, it was necessary to align the feedback form across the two sites, thus creating common guidelines for engaging international groups of students in constructive dialog on technical communication.

Each group of NDSU students filled out a single form to evaluate the UPC presentation to which the group was assigned. The feedback form consisted of a series of prompt questions focusing on different aspects of the oral presentation that had been the focus of the teaching of oral presentations at UPC. Below are the questions related to each of the aspects that make a good presentation.

Target:

- What is the subject of the presentation?

- What audience is the presentation addressed to?

- What is the purpose of the presentation?

Content: What problem are the presenters trying to address?

- What is the main claim?

- Did background information help you understand and appreciate the presentation?

- Is the content of the presentation relevant to the target audience?

\section{Structure:}

- Is the presentation well organized? Does it follow a clear pattern? (Problem-need- solution; chronology; introduction, methods, results, discussion; causes and effects; comparison and contrast.)

- Does the conclusion restate the key points?

- Did you understand the importance of the subject and research? 
- What feedback can you offer on the volume and tempo of the presentation?

- Any observation on body language?

Use of English:

- Do the presenters use appropriate language for the target audience?

- What did you notice about English as a Lingua Franca, i.e., the function of English used by the presenters in terms of pronunciation, word choice, syntax?

General Comments: What are the strengths and weaknesses of this presentation?

\section{Project Implementation and Outcomes The} implementation and outcomes of the project were analyzed from the combined perspectives of instructors and students with the aim of finding out how the notion of effective technical communication is mediated in a globalized learning scenario. Accordingly, analysis focused on the following:

1. Student performance as reflected in

- Feedback forms used by reviewers (NDSU students) to give feedback to authors (UPC students)

- Prelearning and postlearning reports used by the student authors of the presentations to reflect on the technical communication activity.

2. Joint instructor and students' class discussions, first at the respective sites and later when both classes were linked via videoconference, as participants reflected on international technical communication based on the presentations given (by UPC students) and the evaluation done (by NDSU students).

The feedback forms were collected from NDSU student reviewers and analyzed in two stages. First, we examined the questions regarding the rhetorical elements of audience, purpose, and overall organization to find the extent to which the authors of the presentations had been able to effectively target their presentations to the intended communicative situations. Effectiveness was measured in terms of audience reactions, namely, the peer reviewers' reactions. The second stage involved analysis of the answers to the questions regarding delivery and language, the latter focusing on the use of English among non-native speakers. Initially, answers were analyzed for content and grouped together according to the topics mentioned by student reviewers. To group by categories, we merged similar answers but took into account the broad types of questions listed on the form. Our interpretation of answers was guided by the class discussions that served to mediate the project's completion.

The prelearning and postlearning reports that Spanish students submitted were intended to encourage students' reflections by identifying expectations and possible challenges (prelearning) as well as learning outcomes (postlearning report). They were adapted from the forms typically used in TAPP collaborations (described in more detail by Maylath et al. [54]). From all the questions in the prelearning report (on students' linguistic and disciplinary background, expected barriers and learning expectations), for this study, only the question dealing with learning expectations was analyzed. It was further subdivided into specific subquestions about language, email, cooperation, and international cross-cultural interaction.

For the postlearning reports (which contained a variety of questions covering different aspects of communication between partners, technologies used, challenges, satisfaction, etc.), two questions were posed. The first elicited the areas of language and communication that students had focused on during their exchanges (they chose from a series of options: terminology/vocabulary, audience and purpose, grammar, pronunciation, and content). The second asked for overall evaluative comments on their experience. Answers were analyzed by identifying and grouping responses that related to common themes, which were identified and interrelated to answer the question of how engineering students conceptualized and approached technical communication through an experiential learning project.

To complement the feedback forms and the learning reports, class discussions were also examined (from notes taken by the instructors) to identify students' references to language and communication as they reflected on the challenges found and questions raised during the partnership, as well as the final videoconference session, which linked UPC and NDSU students as the former asked questions to clarify the feedback received.

\section{RESULTS}

This section sets out to answer the research question for this study, namely, how can an international oral communication project stimulate engineering students to reflect on rhetorical, 
linguistic, and cultural factors that affect the exchange of technical information?

The findings for the three types of data analyzed-the feedback forms, learning reports, and observations shared during class / videoconference discussions-are presented and discussed in the following three sections.

Feedback Forms (NDSU) In the analysis of feedback forms, we first looked at whether student reviewers could identify the elements of the rhetorical situation of the oral presentations. All groups could identify the purpose of the presentation even if some students observed that purposes should be stated more explicitly in the first part of a technical presentation. In contrast, identifying the target audience was more difficult. Two groups vaguely identified the target audience as "the average person" and "anybody who is not a child that has some technological expertise," respectively. In direct response, when invited to reflect on this feedback during class discussions, many students emphasized the importance of directness and explicitness in technical communication.

Considering the frequency of the problem-solution pattern in engineering communication [55], one of the prompt questions on the feedback form asked reviewers to identify the problem that inspired the process of research and design of a new product/ technological solution. Three out of eight groups reported that the problem was not clearly reported in the presentations. One group observed that more research should have been presented "for why this [product] is necessary." Another group wrote that they understood the importance of the subject but did not understand "what initiated the project."

Feedback on the structure of the presentation was scant. The only weakness identified by three groups was the lack of a proper conclusion. More comments were offered on the delivery of the presentation. Some reviewers observed that the presentation that they reviewed was too slow and full of distracting hesitations and fillers; others, that theirs was too fast. Further criticisms included lack of eye-contact and lack of emphasis and enthusiasm. For the latter, such criticism was directed especially at presentations that seemed to address potential investors.

Some problems emerged with the use of visuals. Although one group simply reported on the lack of visual aids in the presentation that they analyzed, three groups offered more detailed feedback. Two of these three groups observed that some of the pictures included on the slides were distracting rather than helpful because they did not really relate to the presentation's content.

The final section of the questionnaire asked the reviewers to focus on linguistic issues, namely, pronunciation, vocabulary, and syntax. The reviewers' feedback was basically positive in all three areas, although some suggestions for improvement were made regarding vocabulary and pronunciation. Apart from the suggestion to change British English to American English (motorcycle preferred by the Americans over motorbike, fall over autumn, gas instead of petrol), other suggestions included spelling out acronyms and changing Latinate words favored by the native Romance-language UPC students to Anglo-Saxon synonyms favored by the native English-language NDSU students.

Regarding pronunciation, although the majority of reviewers agreed that the presentations were intelligible, a small number of students pointed out problems, mostly related to speed of delivery, an issue that came up during class discussions, with several students being puzzled as to why native speakers of Spanish or Catalan would be so concerned with increasing the speed of their delivery. It appeared that the faster they went, the more they stumbled, and mispronounced words. Yet, the English-language learners seemed to be eager to show confidence and native-like fluency by adopting fast-paced speaking patterns.

Finally, a discrepancy in expectations between the two classes became apparent by the end of the culminating live videoconference: Whereas the UPC students had presumed that they would be making mainly informative presentations, the NDSU students had expected that they would be viewing mainly persuasive presentations. It turned out that the students in the US were attuned to watching sales pitches, with themselves ready to take on the role of investors, rather than as simply an audience of persons interested in learning about the given topics. Such a presumption was probably influenced by the NDSU students' own classwork, which included a sales pitch as one of their assignments unrelated to the TAPP collaboration. It was probably further influenced by their understanding of rhetoric as the art of persuasion-a point of instruction that was emphasized throughout their earlier first-year writing course. In contrast, UPC students had been 
taught both informative and persuasive presentation styles and had been instructed to choose one, leading many students to prepare informative presentations.

Learning Reports (UPC) Spanish students' prelearning reports (a total of 35) and postlearning reports (a total of 29) were analyzed to determine students' expectations preceding the project and the learning outcomes attained by the end of the project. The prelearning report asked, "What do you expect to learn?" This question was further subdivided into cooperation, language use, cross-cultural difference, email conversation, and contacting an unknown foreign partner. By contrast, the analysis of the postlearning report, completed at the end of the term, focused on the language areas to which students had paid attention to during the development of the exchange as well as general comments on the experience.

In their prelearning reports, students emphasized the notion of cooperation through such key words as good cooperation and teamwork. Students also referred to transnational collaboration and the related idea of sharing/exchanging views. Many of the answers linked cooperation with communication, which students described as international and professional, two notions closely related to both the scope of the course and the TAPP partnership.

Students' learning expectations about language use are summarized below:

- Technical/specialized vocabulary

- Register (i.e., technical, formal language)

- Rhetoric (i.e., language appropriate to audience and purpose)

- Correct English (i.e., no mistakes)

The profile that emerges from these students' profiles as English language learners also emerged in some of the answers expecting real feedback from native speakers and even highlighting the idea of sounding nativelike-which reveals a native-speaker-based model of language learning [56]. Pronunciation and speaking skills were also mentioned, as might be expected for a project featuring an oral presentation.

In terms of cross-cultural communication, students expressed their curiosity about and interest in intercultural learning, especially American culture ("there's always something new to learn from other cultures, all good"). More specifically—and probably
TABLE I

Language AREas Mentioned in the Reports

\begin{tabular}{lc}
\hline Area & $\begin{array}{c}\text { Number of } \\
\text { Mentions }\end{array}$ \\
\hline Audience and purpose & 22 \\
Pronunciation & 16 \\
Terminology and vocabulary & 16 \\
Technical contents & 15 \\
Grammar & 10 \\
\hline
\end{tabular}

reflecting their university context-some students referred to intercultural skills for a globalized workplace, such as taking a problem-solving approach to technical communication and the need to adapt to international audiences.

Regarding students' expectations about email writing, three main concepts emerged that relate to the characteristics of this type of writing in international professional contexts.

- Formal and technical (two characteristics mentioned throughout the reports).

- Well-written (including mentions of accuracy, clarity, conciseness, and the use of appropriate tone and style).

- Interculturally appropriate.

Such conceptualization of professional email communication indirectly points to the integrative nature of telecollaborative projects, as a partnership focusing on spoken technical communication involves more wide-ranging learning outcomes, including the written communication that accompanies the main project activities, which help raise students' awareness of the different facets and modes of international professional communication.

For the last question of the prelearning report, expectations about communicating with an unknown foreigner, the concepts that emerged from students' answers included gaining confidence, being open-minded, and improving one's English skills, especially fluency and self-confidence, two aspects that are especially important for non-native learners of ELF for international professional communication.

In their postlearning report, reflecting on the development of the partnership, UPC students reported to have addressed the linguistic topics detailed in Table I in discussions with their partners: 
TABLE II

General Comments In THE Postlearning RePORT

\begin{tabular}{ll}
\hline Positive Remarks & Suggestions for Improvement \\
\hline $\begin{array}{l}\text { Opportunity to give } \\
\text { a real presentation in } \\
\text { English for the first time }\end{array}$ & $\begin{array}{l}\text { Adding additional live } \\
\text { videoconferences }\end{array}$ \\
$\begin{array}{l}\text { Improving speaking } \\
\text { skills }\end{array}$ & $\begin{array}{l}\text { Making smaller groups to } \\
\text { promote more interaction }\end{array}$ \\
Useful feedback & $\begin{array}{l}\text { Extending the partnership for } \\
\text { a longer period of time }\end{array}$ \\
\hline
\end{tabular}

These outcomes show students' concern with topics covered in the course-namely, the rhetorical situation in which the presentation is set-audience and purpose-as well as with specific language difficulties, especially pronunciation. In addition, some of the students included qualitative comments giving more specific details about such revisions, which show students' awareness of language and communication as key to the successful presentation of their projects. Such comments reveal the role of Spanish students as technical experts and owners of projects (congruent with the design of the partnership), a role compatible with that of foreign language learners, asking their native-speaking partners for advice on their English. This two-fold role is reflected in their emphasis on ownership/authorship of projects. They claim knowledge of content while they acknowledge some necessary linguistic revisions in vocabulary, grammar, and pronunciation.

Students stated that their expectations had been fulfilled in terms of improving language, communication, and intercultural skills, as the TAPP project had provided them with a mind-opening experience based on contact with another culture. Oral presentations, the focus of this partnership, were considered a learning outcome and a source of satisfaction (having achieved the demanding task of presenting orally in English). The reactions expressed in their general comments on the activity were highly positive as seen in Table II, which is highly revealing that students' suggestions for improvement involve a more intense partnership with more extensive practice and engagement. Albeit positive, this perception points to a further challenge for instructors, as a more intensive and demanding partnership requires more complex logistics, juggling with calendars and learning activities in both courses, and eliciting from students a sustained level of motivation and commitment for a longer period of time.

An important point regarding the discussion of our findings: We noticed that in their written evaluations and reports, students in Spain focused on producing correct language, whereas the students in the US were more interested in the persuasive power of the presentations. Given the different student profiles, this finding was not surprising. However, an interesting development in the project occurred in final class discussions and the live videoconference, formally closing the project. As they shared their final considerations on the telecollaboration project, the US students shifted their attention to ELF, while the students in Spain set aside linguistic considerations to address the comments on rhetorical strategies offered by the reviewers.

Class Discussions-US: The NDSU class 976

discussions at the end of the project focused mainly on linguistic matters. The reviewers were prepared to reflect on the language used by their peers abroad because pragmatic strategies that are typically used by ELF speakers-explicitness and repetition, for example-were introduced and discussed before the start of the project. A group of reviewers observed that non-native speakers tend to rely on redundancy in spoken communication. Redundancy, they observed, was achieved by adding extra words and prepositions to increase explicitness. An example of a non-native sentence that contains an extra word is "How long time have you studied Spanish?" An example of a sentence that contains an additional preposition is "We have to study about American culture." By adding time in the first example and about in the second, the non-native speakers made their sentences more explicit and their message less ambiguous.

Another group of reviewers understood the use of the plural form of the noncount noun information (a 1013 noncount noun in English, though it is a count noun, informations, in many other languages such as Spanish) as an example of the regularization processes that are typical of ELF. Finally, one of the most important ideas collaboratively developed by the reviewers is that more often than not, what determines miscommunication is a lack of audience awareness and ELF competence, rather than reified cultural differences that allegedly divide people. Lack of ELF competence, for example, resulted in the use of idiomatic expressions that frequently confuse non-native speakers of American 
An example of miscommunication due to unilateral idiomaticity occurred during the final videoconference, when an American student (A) and a Spanish student (S) were sharing comments on the project. What follows is a transcription of their conversation:

A: Your presentation was good, but I could not pick up what you said about the project challenges.

S: Can you repeat please?

A: I could not pick up what your point was on the challenges of the project.

S: Pick up?

In this interaction, the use of the phrasal Germanic verb "pick up" (in probable contrast to the Latinate word "comprehend") confused the Spanish student who already had to cope with the challenges caused by the mediated nature of the exchange. American students consider pick up a simple verb, but this incident shows that good communication is connected to the ability to disambiguate meaning through paraphrase, repetition, and reformulation - pragmatic strategies that are typical of ELF.

Class Discussions-Spain: For Spanish students, the class discussion at project's end was devoted to preparing for the joint videoconference, in which Spanish and US students would meet in real time to clear up and discuss the feedback received. Specifically, in the UPC class discussion, the teams discussed the feedback received on their presentations, so that each of the teams would formulate two questions to their NDSU partners about that feedback. These questions constituted the items on the agenda for the live videoconference with the US students. Apart from asking general questions, such as the weak points of the presentation or the balance between technical and nontechnical information, some students inquired specifically about some of the divergences between both groups' rhetorical conceptualizations (discussed in the reviewers' feedback section of this article). The following question is quite explicit and illustrative of this point, as students expressed their surprise that they had designed an informative presentation, while the US students had expected a persuasive presentation. They problematized this issue by explicitly referring to rhetorical organization and stating that their purpose was informative rather than persuasive.

Regarding the rhetoric, we were a bit surpr since ... we did not want to get into persuading or even convincing, just explain what steps we took and the problems we found, so the question is, how do you think we could make it more clear that the goal was that we were trying to present, it was just informative and to make a report?

Another perspective that emerged from the collaboration between authors of technical presentations, who are learners of English as a foreign language, and reviewers, who are native speakers of the language, is that engineering students may take on a native-speaker model of the language, which would somehow contradict an ELF view of international engineering communication-quite revealing in the students' question asking for advice on how to sound more native-like.

How do you think we could improve our presentation ... to make it look more like English native [presenters] instead of some Spanish students making a presentation in English? Any tricks on improving our native English accent?

In any case, the videoconference discussion helped bring together and contrast students' differing perspectives on international engineering communication.

\section{Discussion}

We return now to our research question: How can an international oral communication project stimulate engineering students to reflect on rhetorical, linguistic, and cultural factors that affect the exchange of technical information?

Our telecollaboration project proved to be effective in stimulating reflections on rhetorical and linguistic strategies for the transmission of technical content. Precisely because the virtual exchange was carried out in English, the lingua franca of technical and professional communication, the project yielded different benefits for non-native versus native speakers.

Takeaways for Spanish Students Feedback from the reviewers prompted presenters to revise certain aspects of their presentation to engage American audiences more effectively. First, Spanish students discovered that English-medium communication in the engineering field requires a higher degree of directness and explicitness in technical presentations. The fact that problems that called for the development of a new technology or purposes of research projects had to be inferred by some of the reviewers slowed down the communication process and often made it difficult 
for the reviewers to appreciate the social and economic benefits of the projects illustrated.

Second, Spanish students developed their linguistic skills, especially technical English, through genuine communication with native speakers in the context of engineering projects. Such interaction boosted the authors' sense of achievement, as they were able to present on complex technical topics in English. Reviewers' observations of vocabulary, pronunciation, speed of delivery, and body language made presenters aware of the need for more practice to further hone their oral communication skills. Having to submit reflection reports on the activity contributed to heightening awareness of technical language and communication while providing the instructor with feedback on how students applied in practice the concepts highlighted during the course, especially adapting to the technical register, with notions such as audience, purpose, or rhetorical organization.

Third, Spanish students became better able to pinpoint particular aspects of communication that needed more attention and more fine-tuning to improve the effectiveness of their oral communication. Their high level of technical expertise and ownership of projects, together with their varied levels of proficiency in English, determined the engineering students' two-fold role in the partnership, simultaneously acting as subject-matter experts (compare with Maylath et al. [34]) and foreign language learners, adhering more to a native-speaker model than to the ELF model that characterizes current international professional communication. As engineering students gain more confidence in their language skills and more experience in communicating with international audiences (native and non-native speakers alike), they will probably develop greater appreciation of ELF models in international professional communication [57] as they put to use not only their English skills but also their multilingual repertoire [13]. Their participation in a partnership like the one presented here is a step forward in gaining intercultural/international professional experience, one of the affordances of telecollaboration [58], [59].

Takeaways for US Students The main takeaway for US students was that international professional communication is an act of mediation. They learned to appreciate the creative resourcefulness that characterizes the use of ELF by observing how their partners in Spain were more adept at accommodating speakers of other languages

because they are regularly exposed to other 1182

languages and intercultural contact. The more they 1183

appreciated the difficulty of the task assigned to $\quad 1184$

the students in Spain, the better they understood 1185

the need to be proactive in creating conditions for a 1186

successful exchange of information. In other words, 1187

they better comprehended the problem of unilateral idiomaticity and understood how accommodation does not proceed along a one-way road that requires speakers of languages other than English to imitate native-like usage to exchange ideas and information. To communicate effectively in the engineering profession, native speakers have to learn how to adjust rhetorical strategies and language use to accommodate different types of users of English.

Second, US students gradually came to conceptualize English as the lingua franca of international professional communication and, hence, as a shared resource for communication-a resource that will be constantly employed by its users to meet varying communication needs.

Third, students developed a new understanding of how rhetorical strategies for oral presentations might shift along cultural lines. What they initially perceived as shortcomings of the presentationslack of directness and explicitness, in particularcame gradually to be seen as alternative ways of conveying technical information that place a heavier burden for interpretation on the audience.

\section{Reflection on Students' Differing Expectations}

Apart from a focus on language (i.e., correct grammar, vocabulary, and pronunciation), Spanish students were also interested in targeting their communication at the right audience and purpose, thus following the guidelines provided in the course. Ironically, it seemed to the US students that their Spanish partners did not always pay attention to identifying a specific audience for their presentations. They also found that the purpose of the presentations was often implied, rather than clearly stated, in line with a rhetorical tradition that places less emphasis on explicitness. These responses show a preference, on the part of the US students, for a more direct communication style in which the aims of a research project or the identification of problems to be solved are stated explicitly at the beginning of a presentation. However, the US students were also invited to reflect on the fact that their Spanish peers were influenced by a rhetorical tradition that places the onus of interpretation on audiences. 


\section{Another explanation for these differing} expectations, as pointed out above, was that, while Spanish students were told that they could target their presentations to a range of (imagined) audiences, including, for example, experts, US students expected a persuasive pitch. Beyond the possibility of clarifying these differing expectations at both sites in future partnerships, we conclude that constructive criticism can benefit authors as they make efforts toward greater explicitness which, in turn, can improve the effects of their future engineering presentations to international audiences. Activities in an international communication context, such as the one spotlighted here, can help engineering students, who are also English language learners, consider rhetorical issues to be as important as producing correct language, thus opening up their perspectives on technical language learning.

A remarkable point to note is that over the years that this partnership has been carried out, the gap between such differing rhetorical traditions has been narrowed, with Spanish students producing more persuasive presentations and making a greater effort to attract the attention of their audiences. Whether influenced by the change in format of the assignment (from traditional oral presentations to creative videos), by the lecturer's guidelines (building on previous years' feedback), by the dialog created by students throughout the virtual exchange, or by the blurring of different rhetorical traditions, we can see that project presentations have gradually become more direct and explicit. An implication that can be derived for further implementations of this partnership would be to ensure dialog during the process (not only in the evaluation of the product) so that students' expectations at both ends are aligned.

Likewise, conducting these partnerships over the years has also influenced instructors' approaches to the task (and to teaching TEC in general). Considering that instructors have to collaborate and negotiate a common task for the TAPP, this exchange also contributes to instructors' professional development as we reappraise our views, tools, and techniques. One of the opportunities - and a challenge-lies in the flexible and exploratory nature of the project, which leads student authors to explore topics as they prepare their presentations for their international partners. This exploration leads to a certain flexibility in the syllabus as students develop curiosity for certain topics. For example, in a later iteration of this partnership, one of the groups became interested in the topic of localization as they planned their pitch for US businesses.

Moving toward more student-centered and flexible TEC curricula is one of the opportunities (and one of the challenges) that open up for TEC instructors. Through observation and analysis of the development of projects, such as the one reported in this article, instructors collaborating internationally can agree on common frameworks and materials for providing meaningful guidance to help engineering students improve their professional communication skills.

\section{CONCLUSION}

A number of implications emerge from this research, among them lessons that can inform the design of technical communication courses. First, the international dimension brought by the virtual exchange helps engineering students to understand how the effective delivery of technical presentations depends on an ability to accommodate audiences and negotiate feedback and other forms of verbal interaction in ELF.

Second, engineering students understand that ethnocentric biases, narrow conceptualizations of rhetorical effectiveness, and a mindless use of native English may disrupt communication in CCVTs. It was startling to see the degree to which US students, drenched as they are in an environment of constant marketing, expected persuasive-oriented pitches, in contrast to Spanish students. Thanks to their virtual exchange, both groups of students became aware of their underlying preferences, those of their partners, and rhetorical styles that they had not considered.

Indeed, for many, as is common to all TAPP partnerships, the workplace realism of an audience beyond a teacher is jarring but most helpful of all in improving their sense of audience, and thus the effectiveness of their language and communication strategies.

It may have been inevitable that the Spanish students would view their native-English US partners as language models across the different iterations of the project. However, greater effort can be made, on the part of instructors, to emphasize a lingua franca model. Positively for the EFL students in Spain, the fact that they could 
communicate effectively with a US audience boosted their confidence in how they perceived their own skills, as reflected in students' positive reactions throughout the project.

A third implication is related to the distribution of roles in virtual exchange projects. In this particular study, the student authors took on the role of owners of the topic and project, while their partners, with whom they interacted, assumed the role of language and communication consultants. The study's findings imply that raising awareness of such roles and what they involve is a useful step that TEC instructors can take from the outset of an exchange. As we and our colleagues have noted elsewhere [59], virtual exchanges featured in TAPP collaborations are common in the globalized workplace; TAPP collaborations allow students to gain valuable practice at performing virtual exchanges effectively while staying in the comfortable, low-stakes setting of an academic class.

We believe that the results of this study, strongly support current calls for organizing IaH initiatives at universities across the world. When the COVID-19 pandemic led to the cancellation of all types of student and faculty travel, including study abroad, at most of the world's universities in March 2020, TAPP collaborations organized for that semester continued to flourish. Indeed, many instructors throughout the TAPP network reported that their students' international collaborations were the single aspect of their courses that was not the least bit disrupted. Thus, students remained connected and shared views and information on a crisis that should unite us globally, rather than produce yet another wave of nationalism and parochialism.

Naturally, continued and deeper research is needed to confirm the findings of this study, and more experimentation should be conducted to understand how telecollaboration projects can help TEC instructors achieve their learning goals. For example, another iteration of our project might reverse the roles, with non-native speakers reviewing the oral presentations of native speakers.
Such research could apply the methods of usability testing to spoken scenarios.

It was observed that in the different phases of the project, participants entered into dialog on topics that are meaningful to them, such as realistic engineering projects and the effect that their presentations produce in an audience. The types of dialog vary each year depending on the courses and students involved. For example, business or language students tend to focus on language and communication aspects, whereas engineering students tend to focus more on the technical details of engineering. Whatever the case, the direction of dialog provides interesting groundwork for critical analysis and further research, which can focus on these multiple dialogs, taking a closer look at questions of ownership—of projects/topics and language-or intercultural pragmatics, as well as the roles of instructors and students in the constructions of such dialogs.

Another promising area of research emerging from projects like this one, which link European and US students, relates to the position of ELF in multilingual contexts. A recent TAPP-related study [60] explored participants' attitudes to ELF and other languages vis-à-vis European language policies. Studying the multilingual nature of many TAPP projects, in which students work across different languages, can yield further insights into the uses and roles of language in global technical and professional contexts, as well as into students' development of their language awareness.

We encourage other TEC instructors to consider designing similar projects to help their students gain audience awareness, intercultural sensitivity, and an understanding of English as a lingua franca. Students and instructors who participate in IaH initiatives like virtual exchange do not simply acquire a set of skills; rather, they become more interested in difference, more curious about diversity, and more open to unfamiliar communication practices. In this way, they embrace an affective disposition that gradually leads to the development of intercultural competence.

\section{REFERENCES}

[1] A. L. Darling and D. P. Donnel, "Practicing engineers talk about the importance of talk: A report on the role of oral communication in the workplace," Commun. Educ., vol. 52, no. 1, pp. 1-16, 2003.

[2] P. Sageev and C. J. Romanowski, "A message from recent engineering graduates in the workplace: Results of a survey on technical communication skills," J. Eng. Educ., vol. 90, no. 4, pp. 985-993, 2001.

[3] M. J. Riemer, "Communication skills for the 21st century engineer," Glob. J. Eng. Educ., vol. 11, no. 1, pp. 89-100, 2007. 
[4] M. C. Paretti and L. D. McNair, "Introduction to the special issue on communication in engineering curricula: Mapping the landscape," IEEE Trans. Prof. Commun., 51, no. 3, pp. 238-241, Sep. 2008.

[5] E. Arnó Macià et al., "Enhancing students' skills in tı cal writing and LSP translation through tele-Collaboration projects: Teaching students in seven nations to manage complexity in multilateral international collaboration," in Proc. 19th Eur. Symp. Lang. Special Purposes, Jul. 2013. [Online] Available: https:/ /typo3.univie.ac.at/fileadmin/user_upload/k_lsp2013/LSP2013_Proceedings / 06_TT/LSP2013_Arno_et_al.pdf

[6] A. Mohan, D. Merle, C. Jackson, J. Lannin, and S. S. Nair, "Professional skills in the engineering curriculum," IEEE Trans. Educ., vol. 53, no. 4, pp. 562-571, Nov. 2010.

[7] J. A. Donnell, B. M. Alley, and A. A. Kedrowicz, "Why industry says that engineering graduates have poor communication skills: What the literature says," in Proc. 118th ASEE Annu. Conf. Expo., 2011.

[8] I. Galván-Sánchez, D. Verano-Tacoronte, S. M. González-Betancor, M. Fernández-Monroy, and A. Bolivar-Cruz, "Assessing oral presentation skills in electrical engineering: Developing a valid and reliable rubric," Int. J. Elect. Eng. Educ., vol. 54, no. 1, pp. 17-34, 2016.

[9] L. De Grez, M. Valcke, and I. Roozen, "The impact of an innovative instructional intervention on the acquisition of oral presentation skills in higher education," Comput. Educ., vol. 53, no. 1, pp. 112-120, 2009.

[10] L. De Grez and M. Valcke, "Student response system and how to make engineering students learn oral presentation skills," Int. J. English Ed., vol. 29, pp. 940-947, 2013.

[11] R. O'Dowd, "From telecollaboration to virtual exchange: State-of-the-art and the role of UNICollaboration in moving forward," J. Virtual Exchange, vol. 1, pp. 1-23, 2018.

[12] B. Seidlhofer, Understanding English as a Lingua Franca. Oxford, UK: Oxford Univ. Press, 2011.

[13] J. Jenkins, "Repositioning english and multilingualism in english as a lingua franca," Englishes Pract., vol. 2, no. 3, pp. 49-85, 2015.

[14] C. Hülmbauer and B. Seidlhofer, "English as a lingua franca in European multilingualism," in Exploring the Dynamics of Multilingualism: The DYLAN Project. A. C. Berthoud, F. Grin, and G. Lüdi, Eds. Amsterdam, The Netherlands: John Benjamins, 2013, pp. 387-406.

[15] D. Kimura and S. Canagarajah, "Translingual practice and ELF," in The Routledge Handbook of English as a Lingua Franca. J. Jenkins, W. Baker, and M. Dewey, Eds. New York, NY, USA: Routledge, 2018 , pp. $295-308$.

[16] J. Jenkins, The Phonology of English as an International Language: New Models, New Norms, New Goals. Oxford, UK: Oxford Univ. Press, 2000.

[17] A. Cogo and J. House. "The pragmatics of ELF," in The Routledge Handbook of English as a Lingua Franca. J. Jenkins, W. Baker, and M. Dewey, Eds. New York, NY, USA: Routledge, 2018, pp. 210-223.

[18] J. House, "English as a lingua franca: A threat to multilingualism?" J. Socioling, vol. 7, no. 4, pp. 556-578, 2003.

[19] A. Cogo and J. Jenkins, "English as a lingua franca i - ope: A mismatch between policy and practice," Eur. J. Lang. Policy, vol. 2, no. 2, pp. 271-294, 2010.

[20] B. Seidlhofer, "Habeas corpus and divide et impera: 'Lrunl english' and applied linguistics," in Unity and Diversity in Language Use, K. Spelman Miller and P. Thompson, Eds. London, UK: Continuum, 2002, pp. 198-217.

[21] B. Seidlhofer, "Accommodation and the idiom principle in english as a lingua franca," Intercultural Pragmatics, vol. 6, no. 2, pp. 195-215, 2009.

[22] B. Mousten, J. Humbley, B. Maylath, and S. Vandepitte, "Communicating pragmatics about content and culture in virtually mediated educational environments," in Computer-Mediated Communication Across Cultures: International Interactions in Online Environment, K. St. Amant and S. Kelsey, Eds. Hershey, PA, USA: IGI Global, 2012, pp. 312-327.

[23] P. Crowther, M. Joris, M. Otten, B. Nilsson, H. Teekens, and B. Wächter, Internationalisation at Home: A Position Paper. Amsterdam, The Netherlands: Eur. Assoc. Int. Educ., 2000.

[24] J. Beleen and E. Jones, "Redefining internationalization at home," in The European Higher Education Area. A. Curaj, L. Matei, R. Pricopie, J. Salvi, and P. Scott, Eds. New York, NY, USA: Springer, 2015, pp. 59-72.

[25] K. M. Soria and J. Troisi, "Internationalization at home alternatives to study abroad: Implications for students' development of global, international, and intercultural competencies," J. Stud. Int. Educ., vol. 18, no. 3, pp. 261-280, 2014.

[26] K. Lundstrom and W. Baker, "To give is better than to receive: The benefits of peer review to the receiver's own writing," J. Second Lang. Writing, vol. 18, pp. 30-43, 2009.

[27] H. Zhao, "New insights into the process of peer review for EFL writing: A process-oriented socio-cultural perspective," Learn. Instruct., vol. 58, pp. 263-273, 2018.

[28] E. Akbari, P. R. J. Simons, A. Pilot, and A. Naderi, "Peer feedback in learning a foreign language in Facebook," Glob. J. Hum. Soc. Sci., vol. 17, no. 2, pp. 31-44, 2017.

[29] S. van Ginkel, J. Gulikers, H. Biemans, and M. Mulder, "Towards a set of design principles for developing oral presentation competence: A synthesis of research in higher education," Educ. Res. Rev., vol. 14, pp. 62-80, 2015.

[30] T. Dudley-Evans and M. J. St. John, Developments in English for Specific Purposes: A Multi-Disciplinary Approach, Cambridge, UK: Cambridge Univ. Press, 1998.

[31] D. Starke-Meyerring and M. Wilson, Eds., Designing Globally Networked Learning Environments: Visionary Partnerships, Policies, and Pedagogies. Rotterdam, The Netherlands: Sense Publishers, 2008.

[32] T. K. Herrington, "Crossing global boundaries: Beyond intercultural communication," J. Bus. Tech. Commun., vol. 24, no. 4, pp. 516-539, 2010.

[33] A. S. Canagarajah, "Lingua franca english, multilingual communities, and language acquisition," Modern Lang. J., vol. 91, no. 5, pp. 923-939, 2007. 
[34] B. Maylath, T. King, and E. A. Macià, "L the US as coauthors: The challenge and collaborating internationally," Connexions: Int. Prof. Commun. J., vol. 1, no. 2, pp. 150-185, 2013.

[35] G. M. Fillenwarth, M. McCall, and C. Berdanier, "Quantification of engineering disciplinary discourse in résumés: A novel genre analysis with teaching implications," IEEE Trans. Prof. Commun., vol. 61, no. 1, pp. 48-64, Mar. 2018.

[36] A. Alaiad, Y. Alnsour, and M. Alsharo, "Virtual teams: Thematic taxonomy, constructs model, and future research directions," IEEE Trans. Prof. Commun., vol. 62, no. 3, pp. 211-238, Sep. 2019.

[37] T. Batova, "Global technical communication in 7.5 weeks online: Combining industry and academic perspectives," IEEE Trans. Prof. Commun., vol. 61, no. 3, pp. 311-329, Sep. 2018.

[38] R. M. Davison, N. Panteli, A. M. Hardin, and M. A. Fuller, "Establishing effective global virtual student teams," IEEE Trans. Prof. Commun., vol. 60, no. 3, pp. 317-329, Sep. 2017.

[39] J. Walwema, "Transliteracies in intercultural professional communication," IEEE Trans. Prof. Commun., vol. 61, no. 3, pp. 330-345, Sep. 2018.

[40] J. B. Humbley, B. Maylath, B. Mousten, S. Vandepitte, and L. Veisblat, "Learning localization through trans-Atlantic collaboration," in Proc. Int. Prof. Commun. Conf., 2005, pp. 578-595.

[41] B. Mousten, B. Maylath, S. Vandepitte, and J. Humbley, "Learning localization through trans-Atlantic collaboration: Bridging the gap between professions," IEEE Trans. Prof. Commun., vol. 53, no. 4, pp. 401-411, Dec. 2010.

[42] B. Mousten, S. Vandepitte, and B. Maylath, "Intercultural collaboration in the trans-Atlantic project: Pedagogical theories and practices in teaching procedural instructions across cultural contexts," in Designing Globally Networked Learning Environments: Visionary Partnerships, Policies, and Pedagogies, D. Starke-Meyerring and M. Wilson, Eds. Rotterdam, The Netherlands: Sense, pp. 129-144, 2008.

[43] B. Maylath, S. Vandepitte, P. Minacori, S. Isohella, B. Mousten, and J. Humbley, "Managing complexity: A technical communication translation case study in multilateral international collaboration," Tech. Commun. Quart., vol. 22, no. 1, pp. 67-84, 2013.

[44] S. Vandepitte, B. Mousten, B. Maylath, S. Isohella, M. T. Musacchio, and G. Palumbo, "Translation competence: Research data in multilateral and interprofessional collaborative learning," in Handbook of Research on Teaching Methods in Language Translation and Interpretation, Y. Cui and W. Zhao, Eds., Hershey, PA, USA: IGI Global, pp. 137-159, 2015.

[45] S. Hammer and B. Maylath, "Real time and social media in trans-Atlantic writing/translation and translation/editing projects," in Emerging Pedagogies in the Networked Knowledge Society: Practices Integrating Social Media and Globalization, M. Limbu and B. Gurung, Eds. Hershey, PA, USA: IGI Global, pp. 144-161, 2014.

[46] I. Piller, Intercultural Communication. Edinburgh, UK: Edinburgh Univ. Press, 2011.

[47] D. S. Bosley, Global Contexts: Case Studies in International Technical Communication. Boston, MA, USA: Allyn \& Bacon, 2001.

[48] B. Thatcher, Intercultural Rhetoric and Professional Communication: Technological Advances and Organizational Behavior. Hershey, PA, USA: IGI Global, 2012.

[49] J. M. Lannon, Technical Communication, 8th ed. Boston, MA, USA: Addison-Wesley, 2000.

[50] K. R. Woolever, Writing For the Technical Professions, 3rd ed. New York, NY, USA: Pearson Longman, 2005.

[51] K. Hyland, "Genre-based pedagogies: A social response to process," J. Second Lang. Writing, vol. 12, no. 1, pp. 17-29, 2003.

[52] D. Dressen-Hammouda, "From novice to disciplinary expert: Disciplinary becoming and genre mastery," English Specific Purposes, vol. 27, pp. 233-252, 2008.

[53] G. Hofstede, Culture's Consequences: International Differences in Work-Related Values. Beverly Hills, CA, USA: Sage, 1980.

[54] B. Maylath, S. Vandepitte, and B. Mousten, "Growing grassroots partnerships: Trans-Atlantic collaboration between American instructors and students of technical writing and European instructors and students of translation," in Designing Globally Networked Learning Environments: Visionary Partnerships, Policies, and Pedagogies, D. Starke-Meyerring and M. Wilson, Eds. Rotterdam, The Netherlands: Sense, 2008 , pp. 52-66.

[55] L. Flowerdew, "A combined corpus and systemic-functional analysis of the problem-solution pattern in a student and professional corpus of technical writing," TESOL Quart. vol. 37, no. 3, pp. 489-511, 2003.

[56] V. Cook, "Going beyond the native speaker in language teaching," TESOL Quart., vol. 33, no. 2, pp. 185-209, 1999.

[57] L. Louhiala-Salminen and A. Kankaanranta, "Professional communication in a global business context: The notion of global communicative competence," IEEE Trans. Prof. Commun., vol. 54, no. 3, pp. 244-262, Sep. 2011.

[58] P. Estes-Brewer and K. St.Amant, "Education and training for globally-distributed virtual teams: Preparing the workforce of the future," Connexions: Int. Prof. Commun. J., vol. 3, no. 1, pp. 3-7, 2015.

[59] B. Mousten, S. Vandepitte, E. Arnó, and B. Maylath, "Preface," in Multilingual Writing and Pedagogical Cooperation in Virtual Learning Environments, B. Mousten, S. Vandepitte, E. Arnó, and B. Maylath, Eds. Hershey, PA, USA: IGI Global, 2018, pp. xv-xxi.

[60] E. Arnó-Macià, S. Vandepitte, P. Minacori, M. T. Musacchio, J. Hanson, and B. Maylath, "A multilingual background for telecollaboration: Practices and policies in European higher education," Eur. J. Lang. Policy, vol. 11, no. 2, pp. 235-255, 2019. 
Elisabet Arnó Macià received the B.A. and Ph.D. degrees in English Studies from Universitat de Lleida, Lleida, Spain, in 1995 and 2006, respectively. She is an Associate Professor of English for Specific Purposes with the School of Engineering, Universitat Politècnica de Catalunya (Barcelona Tech), Vilanova i la Geltrú, Spain. Her research has appeared in such journals as Connexions, English for Specific Purposes, and European Journal of Language Policy. Her latest award-winning anthology is Multilingual Writing and Pedagogical Cooperation in Virtual Learning Environments, co-edited with Birthe Mousten, Sonia Vandepitte, and Bruce Maylath.

Bruce Maylath received the B.A. degree from Kalamazoo College, Kalamazoo, MI, USA, in 1980, the M.A. degree from Michigan State University, East Lansing, MI, USA, in 1987 and the Ph.D. degree from the University of Minnesota, Minneapolis, MN, USA, in 1994 all in English. He is a Professor of English and the Director of Upper-Division Writing at North Dakota State University, Fargo, ND, USA. His research has appeared in such journals as Connexions, IEEE TRANSACTIONS ON PROFESSIONAL COMMUNICATION, European Journal of Language Policy, Journal of Business and Technical Communication, Journal of Specialised Translation, and Technical Communication Quarterly, among others. His latest award-winning anthology is Translation and Localization, co-edited with Kirk St. Amant.
Massimo Verzella received the Ph.D. degree in English: hetoric, Writing, and CulAtre from North Dakota State niversity, Fargo, ND, USA in 2016 and the B.A. degree in oreign Languages and Literatures and the Ph.D. degree in English Language and Literature from the University of Chieti-Pescara, Italy, in 1999 and 2004, respectively. He is an Assistant Professor and Coordinator of English Composition with the School of Humanities and Social Sciences, Pennsylvania State University, The Behrend College, Erie, PA, USA. His main areas of interest are in international professional communication, cross-cultural pragmatics, and translation. His studies have been published in Changing English, Linguistics and Education, and RPCG: Rhetoric, Professional Communication and Globalization.

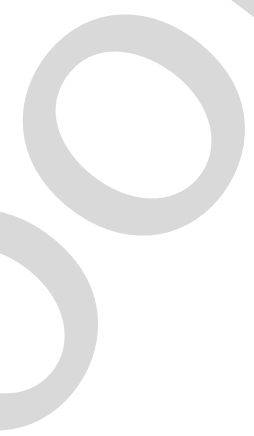

